\title{
The Effect of Polyglycerol Esters of Fatty Acids on the Crystallization of Palm Olein
}

\author{
Janjira Tangsanthatkun, Thunchanok Sonprasert, and Sopark Sonwai* \\ Department of Food Technology, Faculty of Engineering and Industrial Technology, Silpakorn University, 6 Rajmakkanai Road, Nakhonpathom, \\ 73000 THAILAND
}

\begin{abstract}
This research investigated the effect of polyglycerol ester of fatty acids (PGE) on the crystallization of palm olein (POL). Three PGEs were studied: two solid-state PGEs (PGE1105 and PGE1117) and one liquid-state PGE (PGE1155). The addition of 0.5-5\% wt. PGEs influenced the crystallization kinetics of POL and this depended on the type and concentration of the emulsifiers. During cooling down with a cooling rate of $5^{\circ} \mathrm{C} / \mathrm{min}$, the samples containing PGE1105 and PGE1117 started to crystallize at higher temperatures when compared with POL but the crystallization began at lower temperatures for the samples containing PGE1155. All samples with added PGEs exhibited lower solid fat content than that of POL after $12 \mathrm{~h}$ of crystallization time. The number of crystals decreased with an increase in the crystal size with PGE addition but there was no effect on polymorphism. Overall, the results suggested that PGE1105 and PGE1117 enhanced the early stages of POL crystallization possibly via the template effects but suppressed the later stages, whereas PGE1155 delayed the whole process of POL crystallization. The application of POL is often limited by its tendency to get cloudy at low temperatures during long-term storage. Based on the results, 1-5\% wt. PGE1155 could be used to delay or prevent the crystallization of POL at low temperatures.
\end{abstract}

Key words: crystallization, palm olein, polyglycerol ester of fatty acids

\section{Introduction}

Palm oil (PO) is derived from the mesocarp of the palm fruit and is widely used in food applications. It is semi-solid at room temperature $\left(25^{\circ} \mathrm{C}\right)$ and contains similar levels of saturated and unsaturated fatty acids. Generally, PO presents the crystal habit in $\beta^{\prime}$-form, which is usually the most functional polymorph in many fat-based products ${ }^{1)}$. This characteristic combined with other properties such as plasticity, oxidative stability and trans-fat free ensure its beneficial applications in food products ${ }^{2}$. PO may be fractionated into a liquid fraction (palm olein: POL) and a more solid fraction (palm stearin: PS). POL appears clear at ambient temperature of $25^{\circ} \mathrm{C}$ due to its high content of $\mathrm{C}_{18: 1}$ $(39-45 \%)$ and $\mathrm{C}_{18: 2}(10-13 \%)^{3)}$ and has been identified as a good ingredient for several food formulations. However, its application is often limited by its tendency to form granular crystals and get cloudy at low temperature during longterm storage. The visual observation of these crystals is usually seen as a defect by consumers although there is no deterioration in the oil quality ${ }^{4)}$.

The study of the effects of emulsifiers on the crystalliza- tion of fat systems is of great interest for improving the quality of high fat food products such as chocolate, margarines, spreads, confectionery, bakery and dairy products ${ }^{5}$. It is known that emulsifiers can modify the crystallization behavior of fats by either promoting or delaying the crystallization $^{2,6-8)}$. The emulsifiers can interact with the nucleation, crystal growth, and/or polymorphic transitions of fats depending on the miscibility of the emulsifiers and the fats $^{9)}$. The influence of emulsifiers on fat crystallization could also be related to the chemical structure of triacylglycerols (TAGs) in the fat and the emulsifiers where the similarity between their structures leads to co-crystallization and the structural dissimilarity may delay the nucleation and possibly inhibit the crystal growth ${ }^{1,10,11)}$. In addition, emulsifiers can act as heteronuclei, which accelerated the crystallization by direct catalytic action as impurities or seeding effect. The rate of crystal growth can be altered as a consequence of adsorption of the emulsifiers on the fat crystal surface or inclusion in the fat crystals ${ }^{12)}$.

Polyglycerol ester of fatty acids (PGE) are a broad class of food emulsifiers which are produced by polymerization

\footnotetext{
*Correspondence to: Sopark Sonwai, Department of Food Technology, Faculty of Engineering and Industrial Technology, Silpakorn University, 6 Rajmakkanai Road, Nakhonpathom, 73000 THAILAND

E-mail: sonwai_s@su.ac.th

Accepted November 13, 2020 (received for review April 24, 2020)

Journal of Oleo Science ISSN 1345-8957 print / ISSN 1347-3352 online

http://www.jstage.jst.go.jp/browse/jos/ http://mc.manusriptcentral.com/jjocs
} 
of glycerol in the presence of an alkaline catalyst followed by esterification with fatty acids ${ }^{13)}$. The advantageous properties of PGEs are derived from simple modification of their hydrophobicity and hydrophilicity by varying the degree of polymerization of glycerol and esterification with fatty acid moieties ${ }^{14)}$. This gives access to a wide range of HLB values from 3 to 14, popularly used in many different food and nonfood applications ${ }^{15)}$. PGE can be used as a crystallization modifier as they can influence nucleation and crystal growth and modify polymorphic transformation. Petruccelli and Añón ${ }^{16)}$ reported that a PGE rich in $\mathrm{C}_{16}, \mathrm{C}_{18}$ and $\mathrm{C}_{18: 1}(\sim 74 \%$ in total) increased the number of sunflower wax crystals in sunflower oil but decreased the crystal size. Sakamoto et $a l .{ }^{17)}$ revealed that polyglycerol behenic acid ester significantly affected the crystallization properties of PO. With the addition of 1\% wt., the size of PO crystals decreased with an increase in the crystal number, indicating that polyglycerol behenic ester promoted nucleation and inhibited crystal growth of PO. In addition, the XRD patterns showed that, without the PGE, PO crystallized in the $\alpha$ form after rapid quenching to $10^{\circ} \mathrm{C}$ and transformed to the $\beta^{\prime}$ and $\beta$ forms during heating at around 15 and $40^{\circ} \mathrm{C}$, respectively. In contrast, with the PGE, PO crystallized in $\beta^{\prime}$ form at $10^{\circ} \mathrm{C}$ and did not transform to $\beta$-form during heating. Hamada et al. ${ }^{18)}$ reported that a PGE rich in long chain fatty acids $(\mathrm{FA})\left(\mathrm{C}_{16}-\mathrm{C}_{22}\right.$, $60 \%$ in total $)$ and medium chain $\mathrm{FA}\left(\mathrm{C}_{8}-\mathrm{C}_{14}, \sim 40 \%\right.$ in total $)$ decreased the crystallization temperature and suppressed the crystal growth of PO-based biodiesel fuels. A more recent study by Saitou et al. ${ }^{19)}$ showed that the FA composition of PGE is important in controlling the initial step of crystallization. The addition of $0.2 \% \mathrm{wt}$. PGE containing $\mathrm{C}_{16}$ and $\mathrm{C}_{18: 1}$ effectively retarded the crystallization in the diacylglycerol-rich oil whereas the same amount of PGE containing only $\mathrm{C}_{18: 1}$ did not. The retardation of crystallization may be caused by molecular interactions between fats and additives, which occur during the cluster formation processes so that cluster formation is prohibited ${ }^{11)}$.

This research investigated the effect of different types of PGEs (PGE1105, PGE1117 and PGE1155) on the crystallization properties (crystallization kinetics, morphology and polymorphism) of POL. The main objective of this work was to find PGE that could delay the crystallization of POL for industrial use.

\section{Materials and Methods \\ 2.1 Materials}

$\mathrm{POL}(\mathrm{IV}=54.6 \mathrm{~g} \mathrm{I} / 100 \mathrm{~g})$ was kindly supplied by P.P. Oil and Foods Co., Ltd. (Thailand), and was composed mainly of $\mathrm{C}_{18: 1}(41.3 \%), \mathrm{C}_{16}(38.3 \%)$ and $\mathrm{C}_{18: 2}(11.5 \%)$. Three types of PGEs (PGE1105, PGE1117 and PGE1155)were obtained from Palsgaard A/S, Denmark and used without future pu- rification. PGE1105 was composed mainly of $\mathrm{C}_{16}(45.1 \%)$, $\mathrm{C}_{18: 1}(39.3 \%), \mathrm{C}_{18: 2}(7.6 \%)$ and $\mathrm{C}_{18}(5.1 \%)$ and contained $52.4 \%$ of saturated FA in total. The main FA in PGE1117 were $\mathrm{C}_{18: 2}(41.7 \%), \mathrm{C}_{18: 1}(22.8 \%), \mathrm{C}_{16}(20.8 \%)$ and $\mathrm{C}_{18}$ $(12.2 \%)$ with $64.8 \%$ of unsaturated FA in total whereas PGE1155 contained highest content of unsaturated FA $(>$ $89.3 \%$ ) and was composed mainly of $\mathrm{C}_{18: 1}(81.5 \%)$, followed by $\mathrm{C}_{18: 2}(7.1 \%), \mathrm{C}_{16}(5.1 \%)$ and $\mathrm{C}_{18}(3.6 \%)$. PGE1105 and PGE1117 were defined as solid-state surfactants given their paste-like appearance at room temperature, whereas PGE 1155 was considered a liquid-state surfactant given that it is a viscous liquid at room temperature. Blends were prepared by adding $0.5-5 \%$ wt. PGEs to POL and stirred with a magnetic stirrer at $80^{\circ} \mathrm{C}$ until a homogenous sample was obtained.

\subsection{Crystallization and thermal profiles}

The crystallization and melting profiles of the samples were analyzed with the Perkin-Elmer differential scanning calorimeter (DSC) (Model D8000, Perkin-Elmer Co., Shelton, CT, USA) following AOCS method Cj 1-94 ${ }^{20)}$. The instrument was calibrated with indium $\left(\mathrm{mp} 156.6^{\circ} \mathrm{C}\right)$ as a reference standard. A sample of 3-5 mg was placed in an aluminum pan $(20 \mu \mathrm{L}$ capacity $)$ and hermetically sealed with a sample press. An empty pan served as reference. The samples were heated from 25 to $80^{\circ} \mathrm{C}$ and held for 10 min to remove any memory effect. Then they were cooled at $5^{\circ} \mathrm{C} / \mathrm{min}$ to $-60^{\circ} \mathrm{C}$ and held for $30 \mathrm{~min}$ followed by heating at $5^{\circ} \mathrm{C} / \mathrm{min}$ to $80^{\circ} \mathrm{C}$. The crystallization and melting profiles were generated during the cooling and heating, respectively. The profiles were analyzed by the software provided with the DSC.

\subsection{Isothermal crystallization}

The isothermal crystallization at $10^{\circ} \mathrm{C}$ of the samples was studied by using a pulsed-nuclear magnetic resonance (p-NMR) spectrometer (Minispec-mq20, Bruker, Karlsruhe, Germany) to follow changes in solid fat content (SFC) as a function of time. The melted samples were poured into 10 mm O.D. p-NMR tubes to a height of $\sim 4 \mathrm{~cm}$, heated at $80^{\circ} \mathrm{C}$ for $10 \mathrm{~min}$ and then transferred to a cooling bath set at $8^{\circ} \mathrm{C}$. Once the sample temperature reached $10.5^{\circ} \mathrm{C}$, the tube was removed from the cooling bath wiped dry and rapidly put into the p-NMR sample port set at $10 \pm 0.5^{\circ} \mathrm{C}$. The cooling rate was $\sim 20^{\circ} \mathrm{C} / \mathrm{min}$. The $\mathrm{SFC}$ was then continuously recorded for $12 \mathrm{~h}$.

The SFC data were fitted to Avrami equation ${ }^{21)}$ :

$$
-\ln (1-X)=k t^{n}
$$

where, $t$ is time, $k$ is the Avrami rate constant, $X$ is the fractional extent of crystallization at a given time $t$, and $n$ is the Avrami exponent, which represents the dimensionality of growth and type of nucleation. $X$ was taken as the $\mathrm{SFC}$ at any given time normalized by the equilibrium SFC 
$\left(\mathrm{SFC}_{\mathrm{eq}}\right)$ obtained at the end of the crystallization time ${ }^{22)}$. Curve fitting was performed after subtracting the induction time for onset of crystallization ${ }^{23)}$.

In addition, the SFC data were also fitted to the Gompertz equation $^{24)}$ :

$$
F(t)=A e^{-e^{\left(\left(\frac{\mu e(\tau-t)}{A}\right)+1\right)}}
$$

where $F(t)$ fractional extent of crystallization at a given time $t, A$ is the maximum fractional extent of crystallization when $t$ approaches infinity, $\mu$ is the maximum crystallization rate and $\tau$ is the crystallization induction time. Estimation of the Gompertz parameters was performed on the basis of experimental data by non-linear regression and the parameters were used to describe the crystallization kinetics of the samples ${ }^{25)}$.

\subsection{Crystal microstructure}

The microstructure of the samples was observed by using polarized light microscopy (PLM) (Olympus BX51, Olympus Optical Co., Ltd., Tokyo, Japan) equipped with a digital camera (Olympus C-7070, Olympus Optical Co., Ltd., Tokyo, Japan). All samples were melted at $80^{\circ} \mathrm{C}$ for $10 \mathrm{~min}$ and $20 \mu \mathrm{L}$ of each molten sample was placed on the preheated slide and covered by the cover slip. Then, the samples were stored at $10 \pm 0.5^{\circ} \mathrm{C}$ for $24 \mathrm{~h}$ in an incubator. The crystal morphology was imaged by a $10 \times$ lens. The sample temperature was maintained at $10^{\circ} \mathrm{C}$ using Peltier temperature control stage for microscopes(T95-PE Peltier System, Linkam Scientific Instruments Ltd, UK) while the images of the samples were being taken. The Image J software was used to determine the crystal size and the crystallized area of the samples.

\subsection{Polymorphism}

The polymorphic structure of the samples was determined by an x-ray diffractometer (XRD) (MiniFlexII, Rigaku, Japan). The samples were melted at $80^{\circ} \mathrm{C}$ for 10 $\mathrm{min}$ and poured into rectangular plastic moulds $(20 \mathrm{~mm} \times$ $25 \mathrm{~mm} \times 3 \mathrm{~mm}$ ) and then crystallized at $10 \pm 0.5^{\circ} \mathrm{C}$ for $24 \mathrm{~h}$ in an incubator before XRD analysis. Scans were made in wide-angel x-ray scattering (WAXS) from $15^{\circ} 2 \theta$ to $30^{\circ} 2 \theta$ with a scan rate and a step width of $2^{\circ} 2 \theta /$ min and $0.02^{\circ} 2 \theta$, respectively.

\subsection{Statistical analysis}

All experiments were performed in triplicate. The results were analyzed by analysis of variance with least significant difference (ANOVA/LSD) at 95\% confidence interval.

\section{Results and Discussion}

\subsection{Crystallization and melting thermograms}

The most important aspect of the physical properties of fats and oils is related to their crystallization and melting behavior. If the crystallization conditions changed, crystal habit, crystal size and the number of crystals could be affected and these changes will eventually be reflected in the product performance ${ }^{26)}$. The crystallization and melting thermograms of the bulk emulsifiers used in this work are shown in Fig. 1. PGE1105 showed a crystallization peak at $32^{\circ} \mathrm{C}$ and a broad melting peak at the highest peak temperature of $\sim 38^{\circ} \mathrm{C}$ due to its highest content of saturated FA. PGE1117 exhibited one broad crystallization peak at $24^{\circ} \mathrm{C}$ and one broad melting peak at $\sim 36^{\circ} \mathrm{C}$. PGE1155 exhibited one distinct crystallization peak at $-31.9^{\circ} \mathrm{C}$ and one small peak at $1.4^{\circ} \mathrm{C}$. Its melting profile had multiple peaks with the main one locating at $-20.6{ }^{\circ} \mathrm{C}$.

The crystallization and melting thermograms of all POL + PGE samples are presented in Fig. 2. POL began to crystallize with a crystallization onset temperature $\left(\mathrm{T}_{\mathrm{CO}}\right)$ of $5^{\circ} \mathrm{C}$ and showed one crystallization peak at $3.9^{\circ} \mathrm{C}$ flanked by a broad shoulder on the lower-temperature side of the peak (Fig. 2a and Table 1). The result was in line with the DSC crystallization thermogram of POL (IV $=57.7 \mathrm{~g} \mathrm{I} / 100 \mathrm{~g}$ ) reported by Siew and Faridah ${ }^{27)}$. With the addition of 0.5-5\% of PGE1105, the crystallization thermograms exhibited one main crystallization peak but with a broader characteristic than that of POL. $\mathrm{T}_{\mathrm{CO}}$ of all PO + PGE1105 blends increased from that of $\mathrm{POL}(p<0.05)$ and increased with the content of the emulsifier (Table 1), suggesting that PGE1105 induced the crystallization of the higher-melting TAGs in the fat system ${ }^{28)}$ due to the changes in molecular interactions between TAGs and between TAGs and the emulsifi$\mathrm{er}^{19)}$. The increase in $\mathrm{T}_{\mathrm{CO}}$ by the addition of the solid emulsifier was in agreement with previous studies. Basso et $a l .{ }^{29)}$ reported an increase in $\mathrm{T}_{\mathrm{CO}}$ of $\mathrm{PO}$ with the addition of tripalmitin and monoacylglycerols and Domingues et al. ${ }^{1)}$ mentioned that $\mathrm{T}_{\mathrm{CO}}$ of $\mathrm{PO}$ increased with the addition of sorbitan tristearate and sucrose ester(S370). In addition,

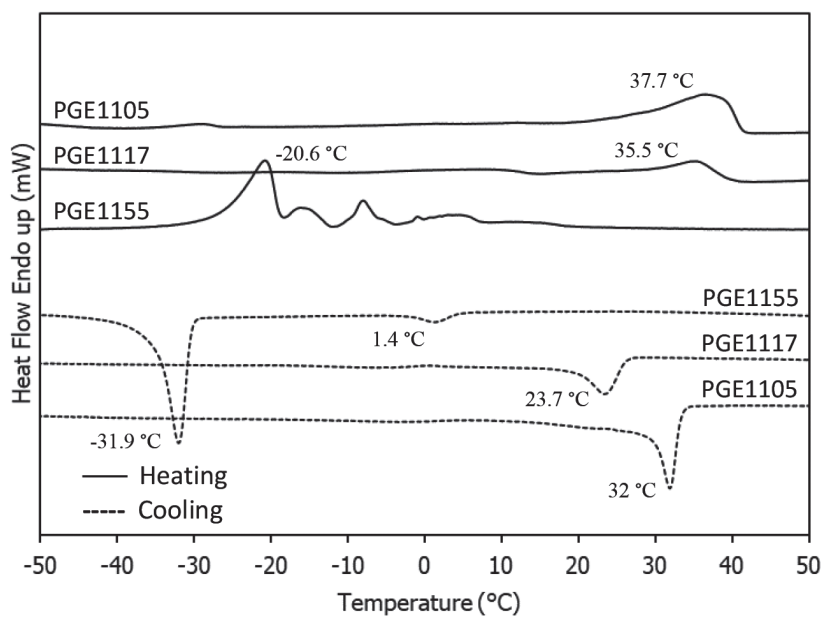

Fig. 1 DSC thermograms for crystallization and melting of bulk emulsifiers. 

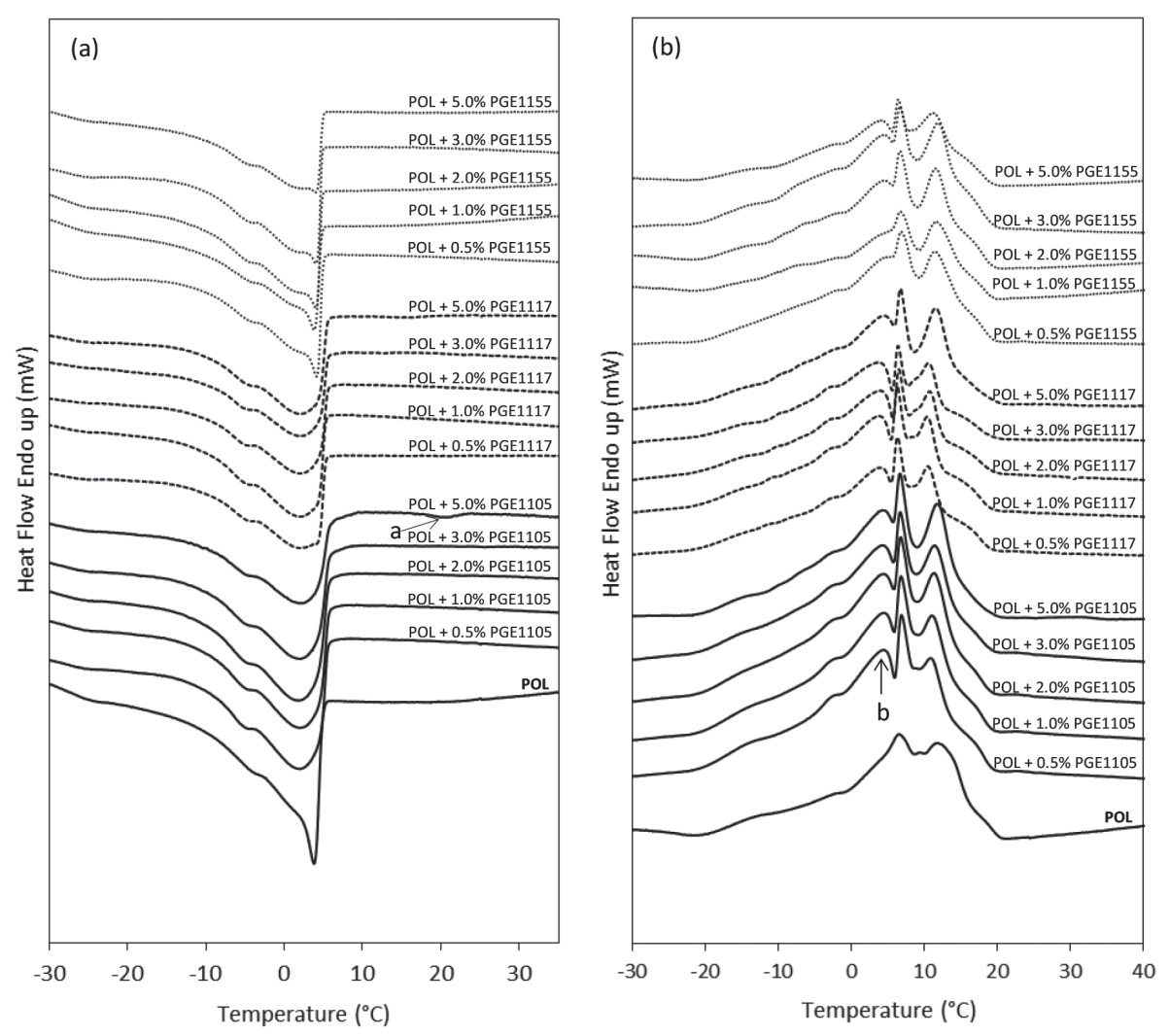

Fig. 2 DSC thermograms for (a) crystallization and (b) melting of POL and its mixtures with different PGEs.

Table 1 Crystallization and melting temperatures and enthalpies for POL with/without the addition of different PGEs.

\begin{tabular}{|c|c|c|c|c|c|c|c|c|}
\hline \multirow{2}{*}{ Samples } & \multicolumn{3}{|c|}{ Crystallization } & \multicolumn{5}{|c|}{ Melting } \\
\hline & $\mathrm{T}_{\mathrm{CO}}\left({ }^{\circ} \mathrm{C}\right)$ & $\mathrm{T}_{\mathrm{C}}$ & $\Delta \mathrm{H}_{\mathrm{C}}(\mathrm{J} / \mathrm{g})$ & $\mathrm{T}_{\mathrm{M} 1}$ & $\mathrm{~T}_{\mathrm{M} 2}$ & $\mathrm{~T}_{\mathrm{M} 3}$ & $\mathrm{~T}_{\mathrm{MC}}\left({ }^{\circ} \mathrm{C}\right)$ & $\Delta \mathrm{H}_{\mathrm{M}}(\mathrm{J} / \mathrm{g})$ \\
\hline POL & $5.0 \pm 0.17^{\mathrm{e}}$ & $3.9 \pm 0.02^{\mathrm{a}}$ & $42.2 \pm 0.21^{\mathrm{a}}$ & & $6.8 \pm 0.00^{\mathrm{a}}$ & $12.3 \pm 0.10^{\mathrm{a}}$ & $20.2 \pm 0.11^{\mathrm{de}}$ & $59.4 \pm 0.14^{\mathrm{de}}$ \\
\hline $\mathrm{POL}+0.5 \%$ PGE 1105 & $5.5 \pm 0.11^{\mathrm{c}}$ & $3.4 \pm 0.35^{\mathrm{b}}$ & $33.8 \pm 0.14^{\mathrm{j}}$ & $5.0 \pm 0.05^{\mathrm{a}}$ & $7.2 \pm 0.14^{\mathrm{a}}$ & $11.3 \pm 0.04^{\text {cde }}$ & $20.2 \pm 0.08^{\mathrm{de}}$ & $57.6 \pm 0.20^{\mathrm{fg}}$ \\
\hline $\mathrm{POL}+1.0 \%$ PGE1105 & $5.6 \pm 0.09^{\mathrm{bc}}$ & $3.5 \pm 0.40^{\mathrm{b}}$ & $36.5 \pm 0.20^{\mathrm{de}}$ & $4.9 \pm 0.14^{\mathrm{ab}}$ & $7.2 \pm 0.15^{\mathrm{a}}$ & $11.6 \pm 0.09^{\text {bcde }}$ & $20.5 \pm 0.19^{\mathrm{bc}}$ & $57.3 \pm 0.25^{\mathrm{fg}}$ \\
\hline $\mathrm{POL}+2.0 \%$ PGE 1105 & $5.6 \pm 0.11^{\mathrm{b}}$ & $3.5 \pm 0.44^{\mathrm{b}}$ & $36.6 \pm 0.19^{d}$ & $4.9 \pm 0.10^{\mathrm{abc}}$ & $7.0 \pm 0.19^{\mathrm{a}}$ & $11.6 \pm 0.17^{\mathrm{bcde}}$ & $20.6 \pm 0.11^{\mathrm{b}}$ & $59.4 \pm 0.31^{\mathrm{de}}$ \\
\hline $\mathrm{POL}+3.0 \%$ PGE 1105 & $5.7 \pm 0.19^{\mathrm{ab}}$ & $3.4 \pm 0.40^{\mathrm{b}}$ & $37.2 \pm 0.11^{\mathrm{c}}$ & $4.8 \pm 0.01^{\mathrm{ab}}$ & $7.1 \pm 0.15^{\mathrm{a}}$ & $11.7 \pm 0.06^{\mathrm{bcd}}$ & $20.5 \pm 0.10^{\mathrm{bc}}$ & $62.5 \pm 0.24^{\mathrm{bc}}$ \\
\hline $\mathrm{POL}+5.0 \%$ PGE 1105 & $5.8 \pm 0.12^{\mathrm{a}}$ & $3.4 \pm 0.38^{\mathrm{b}}$ & $41.6 \pm 0.14^{\mathrm{b}}$ & $4.8 \pm 0.05^{\mathrm{abc}}$ & $6.9 \pm 0.08^{\mathrm{a}}$ & $11.9 \pm 0.03^{\mathrm{ab}}$ & $20.5 \pm 0.08^{\mathrm{bc}}$ & $84.2 \pm 0.24^{\mathrm{a}}$ \\
\hline $\mathrm{POL}+0.5 \% \mathrm{PGE} 1117$ & $5.2 \pm 0.06^{\mathrm{d}}$ & $3.1 \pm 0.06^{\mathrm{b}}$ & $36.0 \pm 0.21^{\mathrm{f}}$ & $4.6 \pm 0.01^{\mathrm{bc}}$ & $7.0 \pm 0.18^{\mathrm{a}}$ & $11.5 \pm 0.31^{\mathrm{cde}}$ & $20.3 \pm 0.13^{\mathrm{de}}$ & $64.0 \pm 0.19^{\mathrm{b}}$ \\
\hline POL $+1.0 \%$ PGE 1117 & $5.3 \pm 0.12^{\mathrm{d}}$ & $3.1 \pm 0.25^{\mathrm{b}}$ & $36.1 \pm 0.13^{\mathrm{f}}$ & $4.6 \pm 0.06^{\mathrm{bc}}$ & $7.0 \pm 0.47^{\mathrm{a}}$ & $11.2 \pm 0.19^{\mathrm{e}}$ & $20.4 \pm 0.07^{\mathrm{cd}}$ & $62.5 \pm 0.26^{\mathrm{bc}}$ \\
\hline $\mathrm{POL}+2.0 \%$ PGE 1117 & $5.5 \pm 0.18^{\mathrm{c}}$ & $3.1 \pm 0.05^{\mathrm{b}}$ & $35.5 \pm 0.22^{\mathrm{h}}$ & $4.8 \pm 0.08^{\mathrm{abc}}$ & $7.1 \pm 0.33^{\mathrm{a}}$ & $11.2 \pm 0.08^{\mathrm{e}}$ & $20.3 \pm 0.11^{\mathrm{cd}}$ & $59.8 \pm 0.23^{\mathrm{d}}$ \\
\hline $\mathrm{POL}+3.0 \%$ PGE 1117 & $5.5 \pm 0.08^{\mathrm{c}}$ & $2.9 \pm 0.00^{\mathrm{b}}$ & $34.8 \pm 0.19^{\mathrm{i}}$ & $4.8 \pm 0.19^{\mathrm{bc}}$ & $7.0 \pm 0.15^{\mathrm{a}}$ & $11.4 \pm 0.25^{\mathrm{de}}$ & $20.3 \pm 0.07^{\mathrm{d}}$ & $59.4 \pm 0.41^{\mathrm{de}}$ \\
\hline $\mathrm{POL}+5.0 \%$ PGE 1117 & $5.5 \pm 0.14^{\mathrm{c}}$ & $2.7 \pm 0.02^{\mathrm{b}}$ & $33.4 \pm 0.15^{\mathrm{k}}$ & $4.8 \pm 0.02^{\mathrm{ab}}$ & $6.9 \pm 0.02^{\mathrm{a}}$ & $11.5 \pm 0.22^{\mathrm{abc}}$ & $21.0 \pm 0.14^{\mathrm{a}}$ & $58.4 \pm 0.31^{\text {def }}$ \\
\hline $\mathrm{POL}+0.5 \%$ PGE 1155 & $4.9 \pm 0.13^{\mathrm{f}}$ & $4.1 \pm 0.00^{\mathrm{a}}$ & $36.4 \pm 0.21^{\mathrm{e}}$ & $4.8 \pm 0.06^{\mathrm{ab}}$ & $7.1 \pm 0.01^{\mathrm{a}}$ & $11.7 \pm 0.03^{\mathrm{abc}}$ & $20.1 \pm 0.16^{\mathrm{de}}$ & $62.2 \pm 0.17^{\mathrm{bc}}$ \\
\hline $\mathrm{POL}+1.0 \%$ PGE 1155 & $4.8 \pm 0.06^{\mathrm{f}}$ & $3.9 \pm 0.18^{\mathrm{a}}$ & $35.8 \pm 0.11^{\mathrm{g}}$ & $4.7 \pm 0.09^{\mathrm{abc}}$ & $7.1 \pm 0.00^{\mathrm{a}}$ & $11.7 \pm 0.14^{\mathrm{abc}}$ & $20.1 \pm 0.12^{\mathrm{e}}$ & $61.6 \pm 0.30^{\mathrm{c}}$ \\
\hline $\mathrm{POL}+2.0 \%$ PGE 1155 & $4.9 \pm 0.11^{\mathrm{f}}$ & $4.0 \pm 0.10^{\mathrm{a}}$ & $35.0 \pm 0.16^{\mathrm{i}}$ & $4.6 \pm 0.00^{\mathrm{bc}}$ & $6.8 \pm 0.02^{\mathrm{a}}$ & $11.8 \pm 0.01^{\mathrm{ab}}$ & $20.2 \pm 0.10^{\mathrm{de}}$ & $56.8 \pm 0.27^{\mathrm{g}}$ \\
\hline $\mathrm{POL}+3.0 \%$ PGE 1155 & $4.8 \pm 0.08^{\mathrm{f}}$ & $4.1 \pm 0.02^{\mathrm{a}}$ & $33.6 \pm 0.09^{k}$ & $4.6 \pm 0.04^{\mathrm{c}}$ & $6.6 \pm 0.02^{\mathrm{a}}$ & $11.8 \pm 0.09^{\mathrm{ab}}$ & $20.2 \pm 0.08^{\mathrm{de}}$ & $57.1 \pm 0.21^{\mathrm{fg}}$ \\
\hline $\mathrm{POL}+5.0 \% \mathrm{PGE} 1155$ & $4.8 \pm 0.15^{\mathrm{f}}$ & $3.9 \pm 0.10^{\mathrm{a}}$ & $33.4 \pm 0.14^{\mathrm{k}}$ & $4.7 \pm 0.02^{\mathrm{abc}}$ & $6.6 \pm 0.04^{\mathrm{a}}$ & $11.7 \pm 0.15^{\mathrm{abc}}$ & $20.2 \pm 0.14^{\mathrm{de}}$ & $56.2 \pm 0.19^{\mathrm{g}}$ \\
\hline
\end{tabular}

Note: For crystallization, $\mathrm{T}_{\mathrm{C}}$ is the crystallization peak temperature and $\mathrm{T}_{\mathrm{CO}}$ is the crystallization onset temperature. For melting, $\mathrm{T}_{\mathrm{M} 1}$ is the melting temperature for the melting peak at lowest temperature and $\mathrm{T}_{\mathrm{M} 3}$ is the melting temperature for the melting peak at highest temperature. $\mathrm{T}_{\mathrm{MC}}$ is the melting completion temperature. $\Delta \mathrm{H}_{\mathrm{C}}$ and $\Delta \mathrm{H}_{\mathrm{M}}$ are the enthalpies of crystallization and melting, respectively. Different letters in the same column are significantly different $(p<0.05)$. 
the sample with 5\% PGE1105 exhibited a small exothermic peak at $\sim 21^{\circ} \mathrm{C}$ (arrow a) which could represent the crystallization of the emulsifier ${ }^{11,30)}$ or a segregation of the highmelting TAGs of POL due to the interactions among TAGs and PGE $1105^{28)}$. Domingues et al. ${ }^{1)}$ showed similar results in relation to the isolated crystallization of S370 at high temperature, accelerating the crystallization of TAGs with high melting point in PO. Verstringe $e t a l{ }^{30)}$ suggested that high-melting monoacylglycerols can initiate the crystallization process and induce fractional crystallization of highmelting TAGs in PO probably with crystallized monoacylglycerols acting as template. The addition of PGE1117 had a similar effect on the crystallization thermogram of POL as PGE1105. The addition of PGE1155 at all concentrations resulted in similar crystallization profiles to POL, but with a decrease in $\mathrm{T}_{\mathrm{CO}}(p<0.05)$, indicating that PGE1155 delayed POL crystallization. The crystallization enthalpy $\left(\Delta \mathrm{H}_{\mathrm{C}}\right)$ of POL was $\sim 42 \mathrm{~J} / \mathrm{g}$ and this value decreased significantly with the addition of all PGEs $(p<0.05)$ with the largest divergence seen with the PGE1155, especially at high concentrations.

The melting thermograms of POL exhibited multiple endothermic peaks (Fig. 2 b) relating to the melting of different groups of TAGs, indicating that there were several types of homogeneous polycrystalline of $\mathrm{POL}^{12)}$. The two main melting peaks of POL were at $\sim 7^{\circ} \mathrm{C}$ and $\sim 12^{\circ} \mathrm{C}$, representing the melting of low- and high-melting fractions. The addition of all PGEs at 0.5-5\% altered the melting thermogram slightly from that of POL with an additional melting peak at $\sim 5^{\circ} \mathrm{C}$ (arrow b). The peak was more prominent with the addition of PGE1105 and PGE1117 compared to PGE1155. In general, the melting completion temperatures $\left(\mathrm{T}_{\mathrm{MC}}\right)$ were not significantly affected by the addition of the three surfactants $(p>0.05)$ (Table 1). The melting enthalpies $\left(\Delta \mathrm{H}_{\mathrm{M}}\right)$ of POL + PGE1105 blends increased as the content of the emulsifier in the blends increased $(p<0.05)$, indicating the more ordered arrangement of POL TAGs. In contrast, $\Delta \mathrm{H}_{\mathrm{M}}$ of POL + PGE 1117 blends and POL + PGE1155 blends decreased as their content in the blends increased $(p<0.05)$.

\subsection{Isothermal crystallization}

The isothermal crystallization curves of POL and POL + PGE blends at $10^{\circ} \mathrm{C}$ are given in Fig. 3 . The shape of the crystallization curve, which is an SFC versus time curve, can give important clues for the crystallization mechanism of a particular fat system. POL started to crystallize at $0.5 \mathrm{~h}$ and showed two-step crystallization with an initial SFC rise to $\sim 2 \%$ within $\sim 1.5 \mathrm{~h}$ (step 1 ) followed by a rapid SFC rise starting at $\sim 3 \mathrm{~h}$ before reaching an equilibrium $\mathrm{SFC}\left(\mathrm{SFC}_{\text {eq }}\right)$ of $\sim 38 \%$ after $12 \mathrm{~h}$ (step 2) (Table 2). This was consistent with what was observed by Zhang et $a l .{ }^{26)}$ during isothermal crystallization of POL at $10^{\circ} \mathrm{C}$.

The crystallization curves of POL + PGEs were different
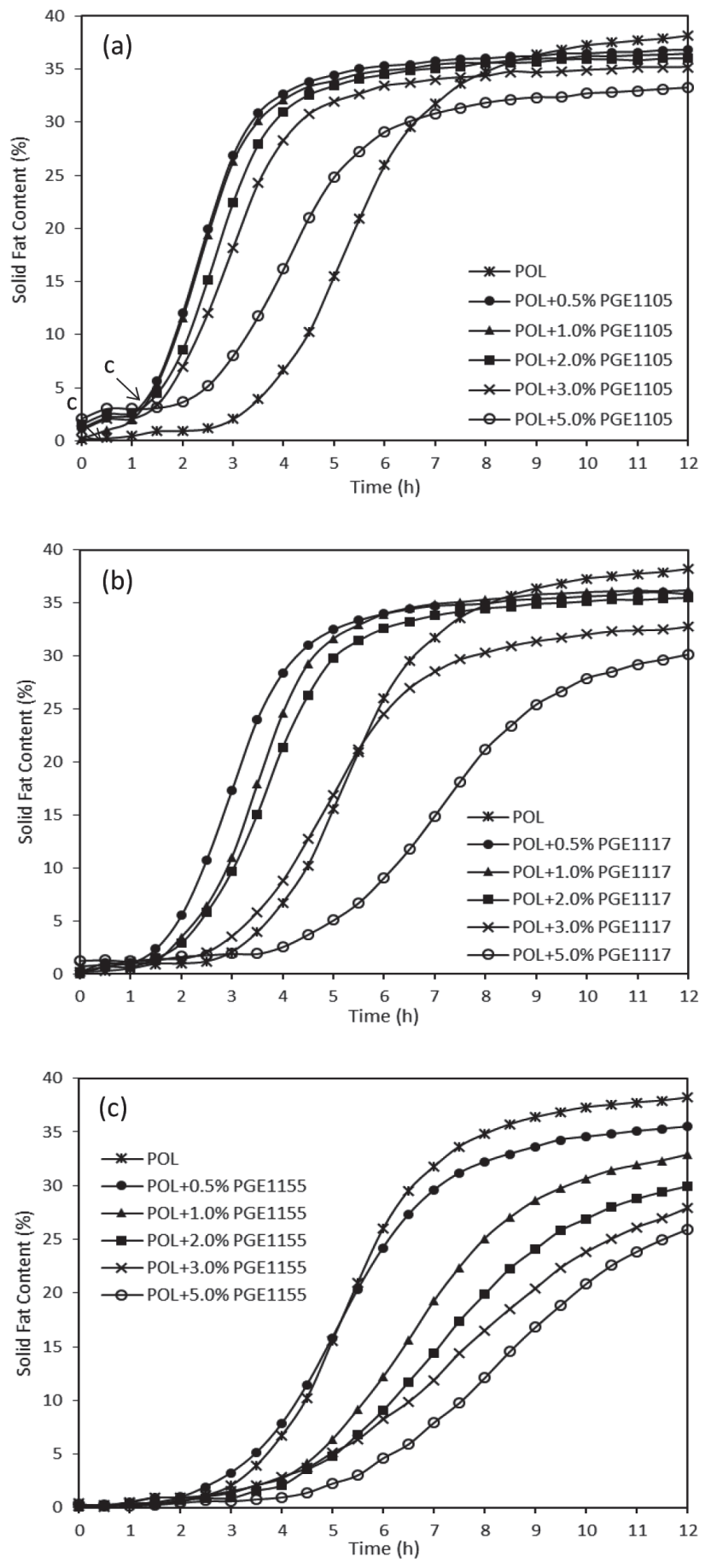

Fig. 3 Crystallization curves of POL and its mixture with (a) PGE 1105, (b) PGE 1117 and (c) PGE 1155 obtained during isothermal crystallization at $10^{\circ} \mathrm{C}$.

from that of POL, an indication of different crystallization mechanisms. PGE1105 did not alter the two-step crystallization pathway of POL (Fig. 3a). However, the samples began to crystallize before the temperature reached $10^{\circ} \mathrm{C}$ during fast cooling with no induction time, suggesting that PGE1105 accelerated the early stages of POL crystalliza- 
Table 2 Equilibrium solid fat content $\left(\mathrm{SFC}_{\text {eq }}\right)$ of POL with/without the addition of different PGEs after isothermal crystallization at $10^{\circ} \mathrm{C}$ for $12 \mathrm{~h}$.

\begin{tabular}{cccc}
\hline \multirow{2}{*}{ Samples } & \multicolumn{3}{c}{$\mathrm{SFC}_{\text {eq }}(\%)$} \\
\cline { 2 - 4 } & PGE1105 & PGE1117 & PGE1155 \\
\hline POL & $38.3 \pm 0.08^{\mathrm{a}}$ & $38.3 \pm 0.08^{\mathrm{a}}$ & $38.3 \pm 0.08^{\mathrm{a}}$ \\
POL $+0.5 \%$ PGE & $37.0 \pm 0.11^{\mathrm{b}}$ & $35.7 \pm 0.12^{\text {cd }}$ & $35.3 \pm 0.09^{\mathrm{d}}$ \\
POL $+1.0 \%$ PGE & $36.4 \pm 0.14^{\mathrm{bc}}$ & $35.9 \pm 0.08^{\text {cd }}$ & $33.0 \pm 0.16^{\mathrm{e}}$ \\
POL $+2.0 \%$ PGE & $36.0 \pm 0.10^{\text {bcd }}$ & $35.5 \pm 0.05^{\text {cd }}$ & $29.7 \pm 0.03^{\mathrm{f}}$ \\
POL + 3.0\% PGE & $35.3 \pm 0.11^{\mathrm{d}}$ & $33.0 \pm 0.11^{\mathrm{e}}$ & $27.7 \pm 0.11^{\mathrm{g}}$ \\
POL $+5.0 \%$ PGE & $33.4 \pm 0.08^{\mathrm{e}}$ & $30.4 \pm 0.17^{\mathrm{f}}$ & $25.8 \pm 0.12^{\mathrm{h}}$ \\
\hline
\end{tabular}

Mean values followed by different letters are significantly different $(p<0.05)$.

Table 3 Avrami rate constant $(\mathrm{k})$ and Avrami exponent $(\mathrm{n})$ for the crystallization at $10^{\circ} \mathrm{C}$ of POL with/without the addition of different PGEs $\left(R^{2}>0.999\right)$.

\begin{tabular}{ccccc}
\hline Samples & & $\mathrm{k}\left(\mathrm{min}^{-1}\right)$ & & $\mathrm{n}$ \\
\cline { 1 - 2 } \cline { 5 - 5 } POL & & $0.040 \pm 0.21^{\mathrm{g}}$ & & $2.47 \pm 0.06^{\mathrm{a}}$ \\
\hline POL $+0.5 \%$ PGE1105 & & $0.435 \pm 0.16^{\mathrm{a}}$ & & $2.33 \pm 0.11^{\mathrm{a}}$ \\
POL $+1.0 \%$ PGE1105 & & $0.418 \pm 0.10^{\mathrm{b}}$ & & $1.87 \pm 0.10^{\mathrm{fg}}$ \\
POL $+2.0 \%$ PGE1105 & & $0.338 \pm 0.23^{\mathrm{c}}$ & & $2.05 \pm 0.13^{\mathrm{bcd}}$ \\
POL $+3.0 \%$ PGE1105 & & $0.284 \pm 0.26^{\mathrm{d}}$ & & $1.77 \pm 0.19^{\mathrm{f}}$ \\
POL $+5.0 \%$ PGE1105 & & $0.206 \pm 0.19^{\mathrm{f}}$ & & $1.86 \pm 0.09^{\mathrm{fg}}$ \\
\hline POL $+0.5 \%$ PGE1117 & & $0.334 \pm 0.21^{\mathrm{c}}$ & & $2.11 \pm 0.12^{\mathrm{b}}$ \\
POL $+1.0 \%$ PGE1117 & & $0.270 \pm 0.11^{\mathrm{e}}$ & & $1.96 \pm 0.16^{\mathrm{de}}$ \\
POL $+2.0 \%$ PGE1117 & & $0.217 \pm 0.13^{\mathrm{f}}$ & & $1.83 \pm 0.14^{\mathrm{g}}$ \\
POL $+3.0 \%$ PGE1117 & & $0.044 \pm 0.19^{\mathrm{g}}$ & & $1.97 \pm 0.08^{\mathrm{de}}$ \\
POL $+5.0 \%$ PGE1117 & & $0.034 \pm 0.10^{\mathrm{gh}}$ & & $2.03 \pm 0.21^{\mathrm{bcd}}$ \\
\hline POL $+0.5 \%$ PGE1155 & & $0.042 \pm 0.24^{\mathrm{g}}$ & & $2.12 \pm 0.19^{\mathrm{a}}$ \\
POL $+1.0 \%$ PGE1155 & & $0.038 \pm 0.14^{\mathrm{gh}}$ & & $2.44 \pm 0.13^{\mathrm{a}}$ \\
POL $+2.0 \%$ PGE1155 & & $0.034 \pm 0.19^{\mathrm{gh}}$ & & $1.97 \pm 0.21^{\mathrm{de}}$ \\
POL $+3.0 \%$ PGE1155 & & $0.036 \pm 0.20^{\mathrm{gh}}$ & & $2.15 \pm 0.16^{\mathrm{bc}}$ \\
POL $+5.0 \%$ PGE1155 & & $0.025 \pm 0.24^{\mathrm{h}}$ & & $2.11 \pm 0.11^{\text {cde }}$ \\
\hline Different letters in the same column are significantly & different $(p<0.05)$.
\end{tabular}

tion. The effect was stronger with higher content of PGE1105. The observed behavior was similar to the effect of solid-state sucrose esters (S170 and P170) on the crystallization of $\mathrm{POL}^{31)}$ and a PO-PS blend ${ }^{32}$. The same effect was also found in the crystallization of cocoa butter with the addition of solid-state sorbitan esters ${ }^{33)}$. After the first step of crystallization, the SFC climbed rapidly to reach a plateau and $\mathrm{SFC}_{\text {eq. }}$. At the beginning of the $\mathrm{SFC}$ increase, there was a crossover in SFC at a time point (arrow c)after which the sample with lower content of PGE1105 showed higher SFC and vice versa. At the end of crystallization time, the sample with higher PGE1105 content showed lower $\mathrm{SFC}_{\text {eq }}(p<0.05)$ (Table 2). This result was in contrast to the effect of $\mathrm{S} 170$ on the $\mathrm{SFC}_{\text {eq }}$ of POL which increased with higher content of $\mathrm{S} 170^{31}$. It is unclear why the concentration responses were different between the emulsifiers, but this suggests that they have different mechanisms in controlling POL crystallization, probably depending on the solubility of the emulsifiers in the oil ${ }^{19)}$.

The crystallization curves of POL + PGE1117 blends demonstrated a more complex behavior than POL + PGE1105 blends (Fig. 3b). The blends containing $\leq 3 \%$ of PGE1117 started to crystallize at approximately the same time as POL $(0.5 \mathrm{~h})$. However, the second step of crystalli- 
Table 4 Gompertz parameters for the crystallization at $10^{\circ} \mathrm{C}$ of POL with/ without the addition of different PGEs $\left(R^{2}>0.999\right)$.

\begin{tabular}{|c|c|c|c|}
\hline Samples & $\tau$ & A & $\mu$ \\
\hline POL & $204.7 \pm 0.00^{\mathrm{de}}$ & $38.2 \pm 0.00^{\mathrm{a}}$ & $0.17 \pm 0.00^{\mathrm{d}}$ \\
\hline POL $+0.5 \%$ PGE1105 & $74.4 \pm 2.99^{\mathrm{g}}$ & $35.9 \pm 0.02^{\mathrm{bc}}$ & $0.26 \pm 0.01^{\mathrm{a}}$ \\
\hline POL $+1.0 \%$ PGE 1105 & $74.7 \pm 5.47^{\mathrm{g}}$ & $36.2 \pm 0.05^{\mathrm{b}}$ & $0.25 \pm 0.00^{\mathrm{a}}$ \\
\hline POL $+2.0 \%$ PGE1105 & - & - & - \\
\hline POL $+3.0 \%$ PGE1105 & - & - & - \\
\hline POL $+5.0 \%$ PGE1105 & - & - & - \\
\hline POL $+0.5 \%$ PGE1117 & $101.0 \pm 3.49^{\mathrm{fg}}$ & $35.5 \pm 0.03^{\mathrm{bcd}}$ & $0.23 \pm 0.01^{b}$ \\
\hline POL $+1.0 \%$ PGE1117 & $127.8 \pm 3.27^{\mathrm{f}}$ & $35.5 \pm 0.03^{\mathrm{bc}}$ & $0.22 \pm 0.00^{\mathrm{b}}$ \\
\hline POL $+2.0 \%$ PGE1117 & $130.4 \pm 3.58^{\mathrm{f}}$ & $35.3 \pm 0.04^{\mathrm{cd}}$ & $0.19 \pm 0.00^{c}$ \\
\hline POL $+3.0 \%$ PGE1117 & $177.0 \pm 6.99^{\mathrm{e}}$ & $32.9 \pm 0.10^{\mathrm{g}}$ & $0.14 \pm 0.00^{\mathrm{e}}$ \\
\hline $\mathrm{POL}+5.0 \%$ PGE 1117 & $266.7 \pm 15.77^{\mathrm{b}}$ & $33.1 \pm 0.13^{\mathrm{fg}}$ & $0.10 \pm 0.01^{\mathrm{g}}$ \\
\hline POL $+0.5 \%$ PGE 1155 & $182.3 \pm 0.00^{\mathrm{e}}$ & $35.2 \pm 0.00^{\mathrm{bc}}$ & $0.14 \pm 0.00^{\mathrm{e}}$ \\
\hline POL $+1.0 \%$ PGE1155 & $242.9 \pm 0.03^{\mathrm{bc}}$ & $34.6 \pm 0.00^{\mathrm{de}}$ & $0.11 \pm 0.00^{\mathrm{f}}$ \\
\hline $\mathrm{POL}+2.0 \%$ PGE 1155 & $250.2 \pm 0.02^{\mathrm{bc}}$ & $33.8 \pm 0.01^{\mathrm{ef}}$ & $0.09 \pm 0.00^{\mathrm{g}}$ \\
\hline POL $+3.0 \%$ PGE1155 & $249.7 \pm 0.01^{\mathrm{cd}}$ & $34.2 \pm 0.01^{\mathrm{e}}$ & $0.07 \pm 0.00^{\mathrm{h}}$ \\
\hline $\mathrm{POL}+5.0 \%$ PGE 1155 & $308.3 \pm 0.03^{\mathrm{a}}$ & $33.1 \pm 0.00^{\mathrm{fg}}$ & $0.07 \pm 0.00^{\mathrm{h}}$ \\
\hline
\end{tabular}

$\tau$ : induction time (min), A: the maximum fractional extent of crystallization (\%), $\mu$ : the maximum crystallization rate $(\% / \mathrm{min})$.

Data fitting were not performed with samples with $2 \%, 3 \%$ and $5 \%$ of PGE1105 due to the lack of the crystallization induction time.

Mean values followed by the different letters in the same column are significantly different $(p<0.05)$.

zation of the blends with $0.5-2 \%$ occurred sooner than POL (at $1.5 \mathrm{~h}$ for $0.5 \%$ and at $2 \mathrm{~h}$ for $1-2 \%$ PGE1117). At the end of the experiments, these samples reached $\mathrm{SFC}_{\text {eq }}$ of $\sim 36 \%$. The blend with 3\% PGE1117 showed a small effect on the early stage of POL crystallization but exhibited a stronger effect on the later stage with a significantly lower $\mathrm{SFC}_{\text {eq }}$ of $33 \%(p<0.05)$. In contrast, the blends with $5 \%$ of PGE1117, although began the first step crystallization before the temperature reached $10^{\circ} \mathrm{C}$, drastically delayed the second step crystallization until $4 \mathrm{~h}$ with a significant drop in $\mathrm{SFC}_{\text {eq }}(30 \%)$ at the end of the experiment compared to POL $(p<0.05)$.

The addition of PGE1155 at all concentrations did not affect the first step of POL crystallization (Fig. 3c). However, the second step of POL crystallization was significantly delayed by all concentrations of PGE1155, except $0.5 \%$. At the end of the experiments, all samples exhibited the $\mathrm{SFC}_{\text {eq }}$ significantly lower than that of $\mathrm{POL}(p<0.05)$. All POL + PGE blends showed lower $\mathrm{SFC}_{\text {eq }}$ than that of POL, suggesting that all PGEs suppressed the later stages of POL crystallization with varying degree. The interaction of the fatty acids of the TAGs and the acyl groups of the emulsifiers was selective and led to different rates of retar- dation and acceleration of crystallization ${ }^{34)}$.

The SFC crystallization curves were fitted to Avrami model via linear regression. The Avrami rate constant( $\mathrm{k}$ ) and Avrami exponent (n)for the crystallization of POL at $10^{\circ} \mathrm{C}$ were 0.04 and 2.47 , respectively (Table 3 ). With the addition of PGE1105 and PGE1117, the k value significantly increased from that of POL $(p<0.05)$, indicating the increase in the driving force for crystallization. The $\mathrm{k}$ values for POL + PGE1105 blends decreased from 0.435 to 0.206 $(p<0.05)$ and the $\mathrm{k}$ values for POL + PGE1117 decreased from 0.334 to $0.034(p<0.05)$ when the concentration of both emulsifiers increased from 0.5 to $5 \%$. In contrast, the $\mathrm{k}$ values for all POL + PGE1155 blends, except the blend with $0.5 \%$ PGE1155, were lower than that of POL $(p>$ 0.05 ) and the $\mathrm{k}$ value decreased as the content of PGE1155 in the blend increased, suggesting that the crystallization of POL was suppressed by PGE1155. The $\mathrm{n}$ values of all POL + PGE blends were between 1.8 and 2.4. The $n$ values can be associated with the mechanisms of crystal growth and fractional numbers for $\mathrm{n}$ values indicate the contribution of more than one crystallization mechanism ${ }^{23)}$.

The SFC crystallization curves fitted to the Gompertz equation revealed that the crystallization kinetics of POL 
were significantly influenced by the addition of PGEs (Table 4). The equation presents an induction time and crystallization rate in crystallization process that depend on the number of nuclei available for crystal growth ${ }^{24)}$. Adding 0.5 and 1\% PGE1105 to POL led to a reduction in the induction time with an increase in the crystallization rate $(p<0.05)$. The addition of $0.5-2 \%$ PGE 1117 also resulted in a decrease in the induction time and an increase in the crystallization rate from that of POL $(p<0.05)$ but $3-5 \%$ PGE1117 decreased the crystallization rate $(p<$ $0.05)$ whereas the addition of all concentrations of PGE1155 cause the crystallization rate to decrease significantly $(p<0.05)$. The results were in line with the data fitting with Avrami model presented above which showed that the crystallization rate generally increased with the addition of PGE1105 and PGE1117 but decreased when PGE1155 was added.

\subsection{Crystal microstructure}

Figure 4 presents the microstructure of POL crystallized at $10^{\circ} \mathrm{C}$ for $24 \mathrm{~h}$ with and without PGE addition. POL exhibited a large number of small spherulites measuring 13.0 $\pm 3.3 \mu \mathrm{m}$ in diameter with some degree of aggregation and a crystallized area of $60.7 \pm 0.4 \%$. The result confirmed that POL can readily form a number of small crystals at low temperature $\left(10^{\circ} \mathrm{C}\right)$, leading to the clouding problem during storage. The addition of PGEs did not affect the crystal shape of POL, with all blends showing spherulitic crystals. However, there were some changes in the crystal number and size compared to POL without additives. 0.5\% PGE1105 did not have any significant effect on the microstructure of POL. As the content of PGE1105 increased further, the crystal size increased significantly from $9.8 \pm$ $3.3 \mu \mathrm{m}$ for $0.5 \%$ PGE 1105 to $46.7 \pm 6.7 \mu \mathrm{m}$ for $5 \%$ PGE $1105(p<0.05)$ with a decrease in the crystallized area (60.6 $\pm 1.9 \%$ for $0.5 \%$ PGE1105 to $43.1 \pm 1.3 \%$ for $5 \%$ $\mathrm{PGE} 1105, p<0.05)$ and a reduction in the number of crystal aggregates. The addition of PGE1117 resulted in a similar trend as that with PGE1105 but with larger crystal sizes measuring $14.4 \pm 4.8$ and $56.5 \pm 11.6 \mu \mathrm{m}$ in diameter for $0.5 \%$ and $5 \%$ PGE 1117 , respectively. The crystallized area also reduced from $55.2 \pm 0.8$ for $0.5 \%$ PGE1117 to $39.1 \pm 0.3 \%$ for $5 \% \operatorname{PGE} 1117(p<0.05)$. The results were in agreement with a previous report by Saitou et al. (2014) which showed a decrease in the crystal number of diacylglycerol-rich oil with an increase in the crystal size due to an addition of PGEs, suggesting that the rate of nucleation was reduced by the addition of PGEs ${ }^{19)}$, but contradicted what was reported by Sakamoto et al. that the addition of polyglycerol behenic acid esters to $\mathrm{PO}$ at $20^{\circ} \mathrm{C}$ led to an increase in crystal number and a decrease in crystal size ${ }^{17)}$. The PLM results with PGE1105 and PGE1117 correlated well with the $\mathrm{SFC}$ results, which showed lower $\mathrm{SFC}_{\text {eq }}$ with increasing PGE concentration(Table 2). The presence of PGE1155 resulted in a smaller increase in the crystal size (from $13.0 \pm 3.5 \mu \mathrm{m}$ for $0.5 \%$ PGE1155 to $28.0 \pm 5.1 \mu \mathrm{m}$ for $5 \%$ PGE1155, $p<0.05$ ) and the formation of noticeably fewer crystal aggregates. The crystallized area ( 32-33\%) did not changed significantly with an increase in the content of PGE1155 ( $p>0.05)$.

\subsection{Polymorphism}

Figure 5 presents the x-ray diffraction patterns of POL with and without PGEs crystallized at $10^{\circ} \mathrm{C}$. The XRD

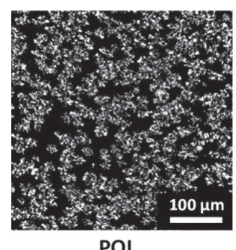

POL

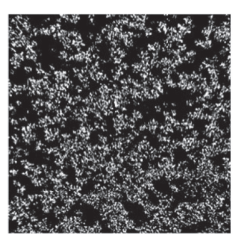

POL+0.5\% PGE1105
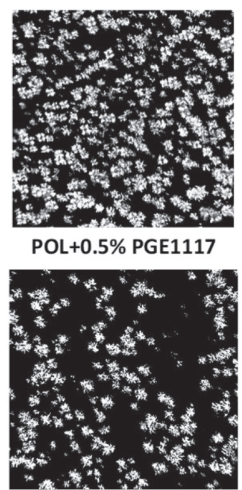

POL+0.5\% PGE1155

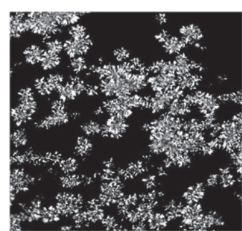

POL+1.0\% PGE1105

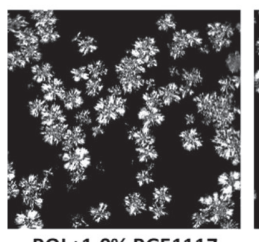

POL+1.0\% PGE1117

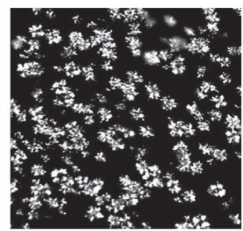

POL+1.0\% PGE1155

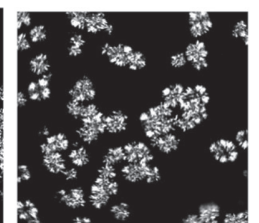

POL+3.0\% PGE1105

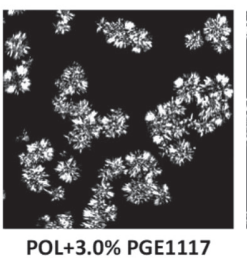

POL+3.0\% PGE1117

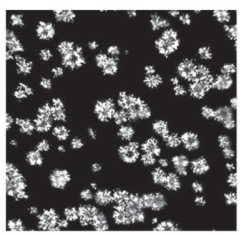

POL+3.0\% PGE1155

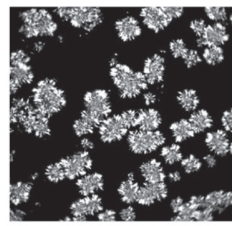

POL+5.0\% PGE1105

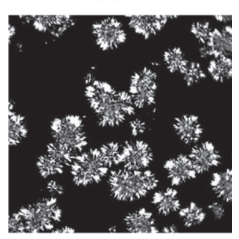

POL+5.0\% PGE1117

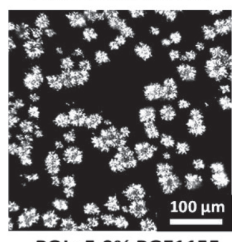

POL+5.0\% PGE1155

Fig. 4 Crystal microstructure of POL and its mixtures with different PGEs obtained after isothermal crystallization at $10^{\circ} \mathrm{C}$ for $24 \mathrm{~h}$. 


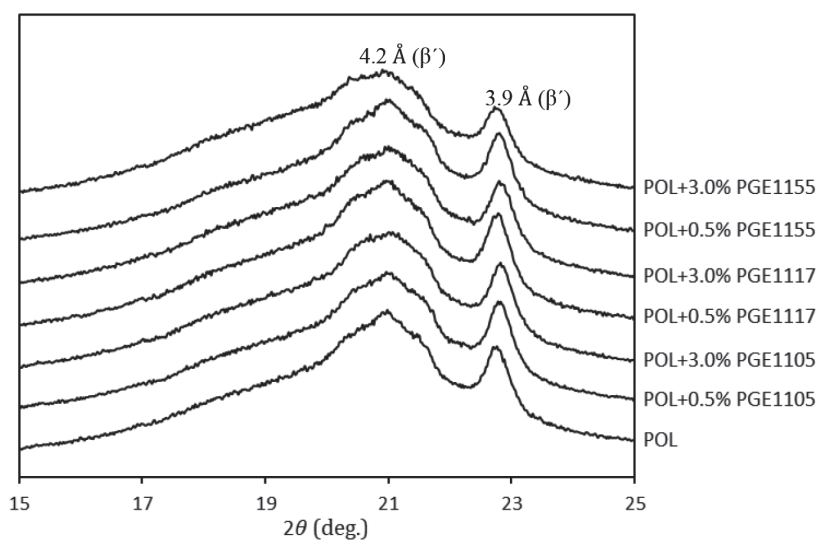

Fig. 5 X-ray diffraction patterns of POL and its mixture with different PGEs obtained after isothermal crystallization at $10^{\circ} \mathrm{C}$ for $24 \mathrm{~h}$.

pattern of POL exhibited two short-spacing peaks at 3.9 and $4.2 \AA$, indicating the occurrence of the $\beta^{\prime}$ form ${ }^{35)}$. In general, $\mathrm{PO}$ is highly stable in the $\beta^{\prime}$ form due to the large amount of TAGs with 50 and 52 carbons which arrange as $\beta^{\prime}$ $\operatorname{crystals}^{28)}$. The addition of PGEs did not affect the POL polymorphism. All POL + PGE blends showed the same diffraction patterns as POL with two short-spacing peaks of $\beta^{\prime}$ form at 3.9 and $4.2 \AA$. Sakamoto et al. reported that the addition of polyglycerol behenic acid esters to PO promote the crystallization of $\beta^{\prime}$ form ${ }^{17)}$.

This study has shown that the addition of PGEs influenced the crystallization kinetics of POL but did not affect the polymorphism. Overall, the results suggested that the solid-state PGEs (PGE1105 and PGE1117) enhanced the early stages of POL crystallization but suppressed the later stages, whereas the liquid-state PGE (PGE1155) delayed the whole process of POL crystallization. When emulsifiers begin to crystallize before the fat during cooling down, the emulsifiers could promote the crystallization of the fat via template effects ${ }^{11)}$ which refer to the phenomenon where a higher melting additive with significant structural and chemical similarities to the lipid serves as templates (seeding nuclei) for heterogeneous crystallisation of lipids $^{36)}$. PGE1105 and PGE1117 have higher melting points than POL, hence could crystallize before POL upon cooling and increase nucleation of POL via template effects ${ }^{11}$. The FA composition of PGEs is important in controlling the initial step of crystallization ${ }^{19)}$ and the concentration $<0.1 \%$ of the emulsifiers may be enough to have a strong impact on nucleation ${ }^{37)}$. PGE1105 exhibited stronger effect during early stages of POL crystallization than PGE1117 probably due to higher degree of similarity between its fatty acid moieties $\left(\mathrm{C}_{16}\right.$ and $\left.\mathrm{C}_{18: 1}\right)$ and those of $\mathrm{POL}^{34,37}$. During the later stages of crystallization, both emulsifiers could be absorbed at the kink sites of crystallizing POL and then prohibit the incorporation of the POL TAGs through large polyglycerol groups ${ }^{19)}$. In contrast, PGE1155, an emulsifier which contained the highest content of $\mathrm{C}_{18: 1}$ in this group, suppressed POL crystallization all the way. It was liquid at $10^{\circ} \mathrm{C}$ hence it did not crystallize before POL to give the template effects. The nucleation retardation may be related to molecular interactions between fat and additives, which occur during the cluster formation process so that the cluster formation is prohibited. The large polar polyglycerol groups of PGE1155 could prevent the POL TAGs from incorporating into clusters and nuclei due to steric hindrance caused by the difference in size of the polar groups ${ }^{19)}$, resulting in the delay in POL crystallization. It was also possible that PGE1155 delayed POL crystallization by preventing the clusters of the fat from forming crystal nuclei through attractive molecular interactions between the emulsifier and the fat molecules (de-clustering effect) ${ }^{11}$.

\section{Conclusion}

PGE1105, PGE1117 and PGE1155 affected the crystallization kinetics of POL and the effect depended on the type and concentration of the emulsifiers. In general, the crystallization induction time decreased and the crystallization rate increased with the addition of PGE1105 and PGE1117. The crystal number and the crystallized area decreased with an increase in the crystal size as the concentration of PGE1105 and PGE1117 in the blends increased. The addition of PGE1117 resulted in an increase in the crystallization induction time and a decrease in the crystallization rate. Overall, PGE1105 and PGE1117 accelerated the early stage possibly via the template effects but suppressed the later stages of POL crystallization. In contrast, PGE1155 suppressed POL crystallization at all time points. The was no effect on the polymorphism of POL by any of the PGEs. Based on the results, PGE1155 could be used to delay or prevent the crystallization of POL at low temperatures.

\section{Acknowledgements}

Funding from Thailand Science Research and Innovation (TSRI) under the 'Research and Researcher for Industries: RRi program' (PHD59I0054) is truly appreciated.

\section{References}

1) Domingues, M.A.F.; Da Silva, T.L.T.; Ribeiro, A.P.B.; Chiu, M.C.; Gonçalves, L.A.G. Structural characteristics of crystals formed in palm oil using sorbitan tristearate and sucrose stearate. Int. J. Food Prop. 21, 618-632 (2018).

2) Martini, S.; Puppo, M.C.; Hartel, R.W.; Herrera, M.L. Effect of sucrose esters and sunflower oil addition on 
crystalline microstructure of a high-melting milk fat fraction. J. Food Sci. 67, 3412-3418(2002).

3) Andreia Schäfer De Martini Soares, F.; Claro da Silva, R.; Caroline Guimarães da Silva, K.; Bertolessi Lourenço, M.; Ferreira Soares, D.; Antonio Gioielli, L. Effects of chemical interesterification on physicochemical properties of blends of palm stearin and palm olein. Food Res. Int. 42, 1287-1294(2009).

4) Siew, W.L.; Ng, W.L. Characterisation of crystals in palm olein. J. Sci. Food Agric. 70, 212-216 (1996).

5) Maruyama, J.M.; Soares, F.A.; D’Agostinho, N.R.; Goncalves, M.I.; Gioielli, L.A.; da Silva, R.C. Effects of emulsifier addition on the crystallization and melting behavior of palm olein and coconut oil. J. Agric Food Chem. 62, 2253-2263 (2014).

6) Awad, T.; Sato, K. Effects of hydrophobic emulsifier additives on crystallization behavior of palm mid fraction in oil-in-water emulsion. J. Am. Oil Chem. Soc. 78, 837-842 (2001).

7) Martini, S.; Herrera, M.L.; Hartel, R.W. Effect of processing conditions on microstructure of milk fat fraction/sunflower oil blends. J. Am. Oil Chem. Soc. 79, 1063-1068 (2002).

8) Sato, K.; Ueno, S. Crystallization, transformation and microstructures of polymorphic fats in colloidal dispersion states. Curr. Opin. Colloid Interface Sci. 16, 384-390 (2011).

9) Garti, N.; Yano, J. in Crystallization Processes in Fat and Lipid Systems (Garti, N.; Sato, K. eds.). Marcel Dekker, New York. pp. 212-250 (2001).

10) Cerdeira, M.; Pastore, V.; Vera, L.V.; Martini, S.; Candal, R.J.; Herrera, M.L. Nucleation behavior of blended high-melting fractions of milk fat as affected by emulsifiers. Eur. J. Lipid Sci. Technol. 107, 877-885 (2005).

11) Shimamura, K.; Ueno, S.; Miyamoto, Y.; Sato, K. Effects of polyglycerine fatty acid esters having different fatty acid moieties on crystallization of palm stearin. Cryst. Growth Des. 13, 4746-4754(2013).

12) Fredrick, E.; Foubert, I.; Van De Sype, J.; Dewettinck, $\mathrm{K}$. Influence of monoglycerides on the crystallization behavior of palm oil. Cryst. Growth Des. 8, 1833-1839 (2008).

13) Wang, F.C.; Marangoni, A.G. Advances in the application of food emulsifier alpha-gel phases: Saturated monoglycerides, polyglycerol fatty acid esters, and their derivatives. J. Colloid Interface Sci. 483, 394403 (2016).

14) Norn, V. Polyglycerol Esters. pp. 110-130 (2007).

15) Younes, M.; Aggett, P.; Aguilar, F.; Crebelli, R.; Dusemund, B.; Filipič, M. Re-evaluation of polyglycerol esters of fatty acids (E 475) as a food additive. EFSA J. 15, doi: 10.2903/j.efsa.2017.50 (2017).

16) Petruccelli, S.; Añón, M.C. Crystallization of waxes in sunflowerseed oil: Effects of an inhibitor. J. Am. Oil Chem. Soc. 68, 684-686 (1991).

17) Sakamoto, M.; Maruo, K.; Kuriyama, J.; Kouno, M.; Ueno, S.; Sato, K. Effects of adding polyglycerol behenic acid esters on the crystallization of palm oil. $J$. Oleo Sci. 52, 639-645(2003).

18) Hamada, H.; Kato, H.; Ito, N.; Takase, Y.; Nanbu, H.; Mishima, S. Effects of polyglycerol esters of fatty acids and ethylene-vinyl acetate co-polymer on crystallization behavior of biodiesel. Eur. J. Lipid Sci. Technol. 112, 1323-1330 (2010).

19) Saitou, K.; Homma, R.; Kudo, N.; Katsuraki, Y.; Sato, K. Retardation of crystallization of diacylglycerol oils using polyglycerol fatty acid esters. J. Am. Oil Chem. Soc. 91, 711-719(2014).

20) AOCS. Official Method and Recommended Practices of the American Oil Chemists' Society. $5^{\text {th }}$ ed. AOCS Press, Champaign, IL (1998).

21) Avrami, M. Kinetics of phase change. II transformation-time relations for random distribution of nuclei. $J$. Chem. Phys. 8, 212-224(1940).

22) Ng, W.L.; Oh, C.H. A kinetic study on isothermal crystallization of palm oil by solid fat content measurements. J. Am. Oil Chem. Soc. 71, 1135-1139 (1994).

23) Puppo, M.C.; Martini, S.; Hartel, R.W.; Herrera, M.L. Effects of sucrose esters on isothermal crystallization and rheological behavior of blends of milk-fat fraction sunflower oil. J. Food Sci. 67, 3419-3426 (2002).

24) Chaleepa, K.; Szepes, A.; Ulrich, J. Effect of additives on isothermal crystallization kinetics and physical characteristics of coconut oil. Chem. Phys. Lipids 163, 390-396 (2010).

25) Foubert, I.; Vanhoutte, B.; Dewettinck, K. Temperature and concentration dependent effect of partial glycerides on milk fat crystallization. Eur. J. Lipid Sci. Technol. 106, 531-539(2004).

26) Zhang, X.; Li, L.; Xie, H.; Liang, Z.; Su, J.; Liu, G. Comparative analysis of thermal behavior, isothermal crystallization kinetics and polymorphism of palm oil fractions. Molecules 18, 1036-1052(2013).

27) Siew, W.L.; Faridah, M.D.J. Compositional and differential scanning calorimetry (DSC) studies of crystals of palm olein. pp. 1-13(2000).

28) de Oliveira, G.M.; Badan Ribeiro, A.P.; dos Santos, A.O.; Cardoso, L.P.; Kieckbusch, T.G. Hard fats as additives in palm oil and its relationships to crystallization process and polymorphism. LWT - Food Sci. Technol. 63, 1163-1170 (2015).

29) Basso, R.C.; Ribeiro, A.P.B.; Masuchi, M.H.; Gioielli, L.A.; Gonçalves, L.A.G.; Santos, A.O. Tripalmitin and monoacylglycerols as modifiers in the crystallisation of palm oil. Food Chem. 122, 1185-1192 (2010).

30) Verstringe, S.; Danthine, S.; Blecker, C.; Dewettinck, K. Influence of a commercial monoacylglycerol on the 
crystallization mechanism of palm oil as compared to its pure constituents. Food Res Int. 62, 694-700 (2014).

31) Tangsanthatkun, J.; Sonwai, S. Crystallisation of palm olein under the influence of sucrose esters. Int. J. Food Sci. Technol. 54, 3032-3041 (2019).

32) Chen, C.; Zhang, H.; Bi, Y.; Cheong, L. Effects of sucrose esters on isothermal crystallization of palm oilbased blend. J. Am. Oil Chem. Soc. 92, 277-286 (2015).

33) Sonwai, S.; Podchong, P.; Rousseau, D. Crystallization kinetics of cocoa butter in the presence of sorbitan esters. Food Chem. 214, 497-506 (2017).

34) Miskandar, M.S.; Man, Y.B.C.; Rahman, R.A.; Aini, I.N.;
Yusoff, M.S.A. Effects of emulsifiers on crystal behavior of palm oil blends on slow crystallization. J. Food Lipids 14, 1-18(2007).

35) Larsson, K. Classification of glyceride crystal forms. Acta Chem. Scand. 20, 2255-2260 (1966).

36) Bayés-García, L.; Patel, A.R.; Dewettinck, K.; Rousseau, D.; Sato, K.; Ueno, S. Lipid crystallization kinetics-roles of external factors influencing functionality of end products. Curr. Opin. Food Sci. 4, 32-38 (2015).

37) Smith, K.W.; Bhaggan, K.; Talbot, G.; van Malssen, K.F. Crystallization of fats: Influence of minor components and additives. J. Am. Oil Chem. Soc. 88, 1085-1101 (2011). 